\title{
Impact characteristics of sugar beet root during postharvest storage
}

\author{
Pawet Kołodziej (1), Krzysztof Gołacki (1)*, and Marek Boryga (D) \\ Department of Mechanical Engineering and Automatic Control, University of Life Sciences in Lublin, \\ Głęboka 28, 20-612 Lublin, Poland \\ Received September 18, 2018; accepted March 6, 2019
}

\begin{abstract}
The effects of time of sugar beet root storage on the parameters determined by impact testing were studied. The $9 \mathrm{~mm}$ diameter and $20 \mathrm{~mm}$ high cylindrical samples were cut crosswise and lengthwise along the root axis. The impact velocity was $1 \mathrm{~m} \mathrm{~s}^{-1}$ and the change in the response force over time was observed at both ends of the sample. The measurements were made directly after harvesting and after $24,48,96$ and $120 \mathrm{~h}$ of storage at room temperature. Failure stress and strain, impact energy, absorbed energy, Young's modulus and shock wave speed were determined in the sample tissue from the change in the response force at both ends of the sample. A drop of $40 \%$ in the average values of the energy required to damage the samples was observed during $120 \mathrm{~h}$ of storage. A similar dependence was found for the energy absorbed by the sample as evidenced by the greater susceptibility of the roots to impact loads. The experiment confirms the importance of critical stress criterion for cylindrical samples of sugar beet. The velocities of shock wave propagation obtained from the samples during impact were in the range of $220-384 \mathrm{~m} \mathrm{~s}^{-1}$ and were not correlated with the other experimental parameters.
\end{abstract}

Keyw ord s: sugar beet root, impact energy, absorbed energy, storage time

\section{INTRODUCTION}

Plant materials including sugar beets are characterized by high water content levels and are particularly exposed to damage during harvesting, cleaning processes, clamp building, transport and factory intake. Most sugar beet damage is the result of a mechanical load of a dynamic character where stress propagates in the wave form. The nature of this kind of load differs from those under quasistatic conditions as biological material loses its viscoelastic properties over time and behaves as an elastic-plastic body.

*Corresponding author e-mail: krzysztof.golacki@up.lublin.pl
Moreover, the behaviour of beet under an impact load is substantially affected by its mass. The actual load of the dynamic character is observed when the deforming element results in the considerable displacement of one end of the sample whereas the other end is not distorted because the stress wave does not reach it. The threshold velocity, above which the load is of a dynamic character, depends on the characteristics of the material, particularly the density and rigidity. The different nature of the deformations of a quasistatic and dynamic character results in a different degree of resistance of the materials to various types of mechanical loads (Stropek et al., 2014; Gołacki et al., 2014; Kołodziej et al., 2014; Stropek and Gołacki, 2018). Therefore the strength parameters of sugar beet roots should be determined under dynamic load conditions. It should be taken into account that a fall from a height of $2.5 \mathrm{~cm}$ results in an impact with a $0.7 \mathrm{~m} \mathrm{~s}^{-1}$ velocity which in the case of most fruit and vegetables generates a stress wave and results in the deterioration of its material and consumption qualities. Despite improvements in the technological operations performed on sugar beet roots, damage still occurs, which in turn affects the final crop and production costs. Mechanical damage may be divided into three basic groups (Skalicky, 2003):

- damage due to harvesting (breaking off ends, indentations, improper trimming and leaving undug roots in the field);

- damage caused by cleaning and transporting units of the harvester;

- damage resulting from roots falling during transport or dumping while unloading.

(C) 2019 Institute of Agrophysics, Polish Academy of Sciences 
Invisible cracks of the root are of significant danger because they lead to infections causing sugar loss from $0.2 \%$ per day and $0.34 \%$ per night (Wiltshire and Cobb, 2000).

In order to limit mass losses, reduce production costs and improve raw material qualities numerous studies under impact and quasi-static loads were carried out. The most frequently determined mechanical parameters of sugar beet roots are maximal destructive force, deformation energy, inclination of force/displacement curve and compressibility. Alizadeh and Segerlind (1997) determined the ranges of Young's modulus variability, coefficient of Poisson and critical stress based on the test of cylindrical root sample compression. Young's modulus increased during the 35 days of harvesting. While studying cylindrical samples in a mono-axis compression test Gorzelany and Sosnowski (2003) determined the average value of the damaging force for fresh beets and those stored for 60 days. They noted a great increase in the damaging force after storage. Gorzelany and Matłok (2014) found some differences in the damaging force value depending on the variety studied. Nedomova et al. (2017) compared the effectiveness of the tests of mono-axis compression of free sample and the penetration test during a 77 day storage period. They found that the root strength increases with storage time compared to the results obtained in the penetration test.

Pan et al. (2015) determined the three mechanical parameters of axially compressed sugar beet samples. These were: the maximal damaging force of a $23 \%$ strain, the area below the force-displacement curve and the inclination of the force-displacement curve. Investigations were carried out to check the possibility of predicting various properties of sugar beet roots by means of visible and near-infrared spectroscopy. These methods were effective for the determination of both moisture and sugar contents. However, they proved to be inadequate for the evaluation of mechanical parameters determined in the compression test. The authors postulate the necessity of the elaboration of new effective methods for the determination of the mechanical properties of both samples and whole sugar beet roots.

Plant materials consist of single cells, which form a tissue structure. The cells are characterized by various shapes, sizes, widths, orientations as well as thicknesses of the cellular walls (Gancarz et al., 2014; Karim et al., 2018). These features, can affect the susceptibility of plant material to loading forces originating from various directions in relation to the axis of the studied tuber/fruit. Gancarz (2016) found a relationship between the size of potato cells and of the occurrence of black spot in potato tubers after storage. Exterior loading was realized according to the constant height multiple impacts method (CHMI). Tissue resistance to mechanical loading also depends on the water potential, more precisely the turgor potential of the tissues. Studies by Zdunek et al. (2008) using the acoustic emission method showed the effect of the turgor level on the failure mode of potato cellular structures. In the case of hydrated cells (strong adhesion) it was necessary to use low energy levels for the disruption of cellular walls due to some initial cell wall tension. The cells, which have a high turgor value (relatively high degree of cell adhesion) are damaged by rupturing and those, which are less hydrated, are damaged by cell-cell deboning.

Bentini et al. (2005) made tests of sample compression and impact on beet roots just after harvesting and five hours after they were dug out. The critical stress for the samples cut crosswise and lengthwise along the root axis, the apparent modulus of elasticity and Poisson coefficient were determined using the compression test. Maximal acceleration during the impact change of velocity and time of impact were determined by means of the impact test. The dependence of the average values of the Poisson coefficient on the load applied during the test was determined and it was found that these values increase with loading for fresh roots. A significant spread in the average values of parameters determined in the quasi-static and impact tests did not allow the authors to draw conclusions about root resistance to damage under various load conditions. A significant achievement of the research was the determination of essential changes in the mechanical parameters of beets left in the field for five hours which should be taken into account in the choice of harvest handling technology.

As stated above, mechanical damage to sugar beet roots mainly results from loads of a dynamic character. The working parts of agricultural machinery e.g. diggers, star cleaners, platform and rod augers reach great linear and angular velocities (Pilbrow, 1997). They contribute to the loads to which beet roots are subjected: $25 \mathrm{~g}$ in the case of cleaning stars and about $35 \mathrm{~g}$ for platform augers (Schuh et al., 1997). The authors registered the largest values of acceleration just after digging out, this value was detected on the platform augers using an "electronic beet" (Bartlett 1998; Hopkinson and Houghton, 1998; Bentini et al., 2002). Moreover, frequent impacts of roots due to falls during loading and unloading fully justify the requirement to become familiar with the mechanisms of sugar beet tissue deformation under dynamic load conditions.

The most frequently applied impact study methods are drop tests (Lewis et al., 2007; Celik et al., 2011; Ozbek et al., 2014; Shafie et al., 2015; Ragni and Berardinelli, 2001) as well as tests involving the use of a pendulum (Yen and Wan 2003; Opara et al., 2007; Polat et al., 2012; Stropek and Gołacki, 2016b; Abedi and Ahmadi, 2014; Stropek and Gołacki, 2019a, 2019b).

Trnka et al. (2018) also applied a non-destructive method to study sugar beet root response on impact using a laser vibrometer. The root was stimulated with vibrations by means of an impact with a cylindrical bar. The spectrum of the vibrations frequency of the point located on the side surface of the root possessed the maximal value which characterized the rigidity of the studied root. 
The aim of the paper was to determine the effects of the sugar beet root storage time on the values of structural parameters obtained in the impact test of cylindrical samples such as: maximal force of sample response, damaging energy, energy absorbed by the sample, Young's modulus, velocity of stress wave propagation in the sample as well as the levels of stress and strain which damage the sample. The effect of sample orientation on the value of the abovementioned parameters was also studied.

\section{MATERIALS AND METHODS}

The stand designed to test the samples for the cylindrical shape impact study consisted of a pendulum with a rigid $940 \mathrm{~mm}$ long arm. A cylindrical hammer with a $3.5 \mathrm{~kg}$ mass and an Endevco model 2311-100 piezoelectric force sensor of $2 \mathrm{mV} \mathrm{N}^{-1}$ sensitivity and a measuring range of $222.5 \mathrm{~N}$ was installed on the end of the pendulum (Fig. 1) (Stropek and Gołacki, 2016a; Bajema et al., 1998). An identical sensor was installed in the anvil placed on the steel plate which was fixed to the concrete bearing wall of the building.

The pendulum axis was connected with the angular displacement sensor WMU-45-SK which worked in the range $\pm 45^{\circ}$. The sensors were connected to a four-channel measurement card of changing sampling frequency in the range from 1 to $153.6 \mathrm{kHz}$. The measurement results were collected and registered by means of a computer with specially customized software. The cylindrical samples of sugar beet roots were fixed to a plate attached to the sensor by means of technical vaseline. A similar plate was attached to the sensor positioned on the hammer. The difference of velocity of the hammer set motion due to the gravitational force on a $5 \mathrm{~mm}$ section of the sample being crushed is $0.01 \mathrm{~m} \mathrm{~s}^{-1}$. However, it should be noted that the sample resisted crushing, which reduced the above-mentioned difference of velocity. Taking that into account, a constant velocity of sample deformation during impact was assumed.

Sugar beets of the IMPERIAL variety were the experimental material, cylindrical samples of diameter $\varnothing=9 \mathrm{~mm}$ were cut from the central part of the root crosswise and lengthwise to their axes using a punching die (Fig. 2).

The samples were cut at a height $\mathrm{H}=20 \mathrm{~mm}$. Tests were performed on fresh roots and those stored at room temperature for: 24, 48, 96 and $120 \mathrm{~h}$. The samples were deformed by $5 \mathrm{~mm}$ which was sufficient for stable damage to occur. When the sample was placed in the measuring head it was impacted at a velocity of $1 \mathrm{~m} \mathrm{~s}^{-1}$, which was possible owing to pendulum deflection by an angle of $16.5^{\circ}$.

The experiment involved the application of the impact force on the sample with a simultaneous registration of the response force-time curves at both ends. Due to the kinetic energy of the hammer being many times larger at the time of impact compared to the sample deformation by $5 \mathrm{~mm}$, a constant velocity of deformation equal to $1 \mathrm{~m} \mathrm{~s}^{-1}$ may be assumed. This made it possible to calculate the energy required for sample damage from the equation:

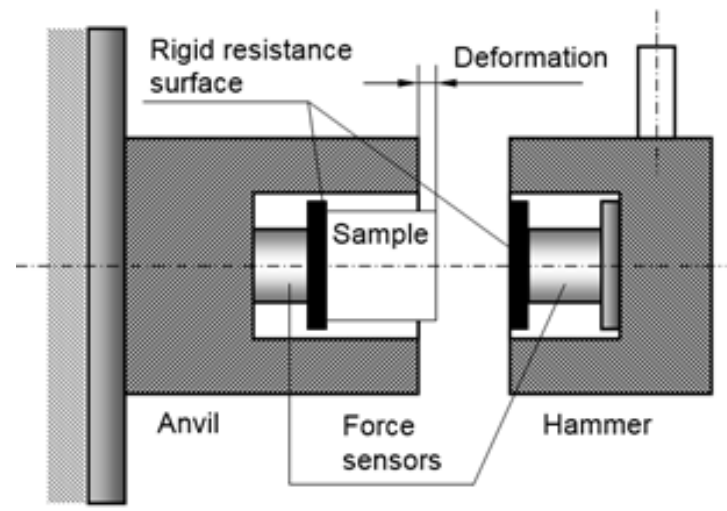

Fig. 1. Scheme of the measuring head of the stand for studying the course of the sugar beet root response force.

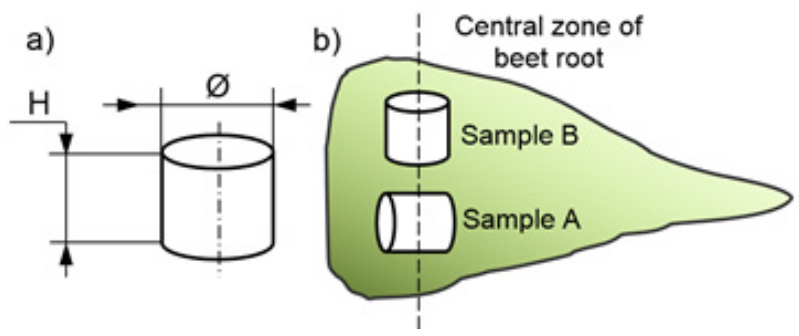

Fig. 2. Shape and size of the sample (a), zone of the samples cut out (b).

$$
e_{i}=v \int_{0}^{t_{c}} F_{h}(t) d t,
$$

where: $v$ - the velocity of the hammer at the impact time $\left(\mathrm{m} \mathrm{s}^{-1}\right), F_{h}(t)$-force generated by the sample as a response to the action of the hammer $(\mathrm{N})$ as a function of time, $t_{c}-$ the time from the beginning of the test to the point where the maximal value of the impact force was reached.

Knowing the response force-time curves at both ends of the sample it was possible to calculate the energy absorbed by the sample during impact:

$$
e_{a b}=v \int_{0}^{t_{c}}\left[F_{h}(t)-F_{a}(t)\right] d t,
$$

where: $F_{h}(t)$ - the response force-time function on the hammer during the impact $(\mathrm{N})$ and $F_{a}(t)$ - the response force-time function on the anvil during the impact.

The stress $\sigma_{d}$ and the damaging deformation $\varepsilon_{d}$ were determined using the expression:

$$
\sigma_{d}=\frac{F_{h \max }}{A} ; \varepsilon_{d}=\frac{\Delta l}{l},
$$

where: $F_{h \max }$ - the maximal value of the sample response force registered on the hammer $(\mathrm{N}), A$ - the sample crosssection surface area $\left(\mathrm{mm}^{2}\right), \Delta l$ - the linear displacement of the hammer corresponding to the maximal impact force $(\mathrm{mm}), l-$ the preliminary length of the sample $(\mathrm{mm})$.

The value of the linear elasticity - the apparent Young's modulus $E_{d}$ was determined from the dependence: 


$$
E_{d}=\frac{\sigma_{d}}{\varepsilon_{d}}=\frac{F_{h \max } l}{A \Delta l} .
$$

The values $\Delta l$ were determined from the expression:

$$
\Delta l=v t_{c},
$$

where: $v$ - the velocity of the hammer at the time of impact $\left(\mathrm{m} \mathrm{s}^{-1}\right)$.

The velocity of stress wave propagation in the sample $v_{w}$ was found based on:

$$
v_{w}=\frac{l}{\Delta t},
$$

where: $\Delta t-$ the time between the starting point of response force-time curve and the point from which the response force starts to increase, registered on the hammer and anvil.

Statistical analyses of the obtained investigation results were made based on the software Statistica ver. 13.1. These were of average differences significance of all parameters for different storage time as well as regression ones. Totally 150 samples were examined.

\section{RESULTS AND DISSCUSSION}

The typical course of the sample response force which registered on the hammer and anvil is presented in Fig. 3. It shows that part of it which occurred until the time of sample damage which was observed when the extent of deformation was about $2.7 \mathrm{~mm}$. A lower course was noted at the end of the sample which was not deformed. The area between the two courses of the response force is proportional to the energy dispersed in the sample during impact.

In the experimental results no statistical significance of the dependence between the parameters obtained for the samples which were cut lengthwise and crosswise relative to the root axis in all of the days of the experiment was found. Therefore in this paper all of the results for both kinds of samples are presented cumulatively.

The effect of storage time on the value of the force damaging the sample is presented in Fig. 4. The average values obtained from the tests just after harvesting and for the roots stored for $24 \mathrm{~h}$ were 181.2 and $175.2 \mathrm{~N}$, respectively. However, after the second and fourth days of storage the damaging force decreased significantly to a value of $154.7 \mathrm{~N}$ and reached 146.6 $\mathrm{N}$ after four-days of storage.

In the case of the energy necessary for damaging the sample, a statistically significant drop was noted with the storage time. The average values of the damaging energy were $264.010^{-3} \mathrm{~J}$ just after harvesting and $131.110^{-3} \mathrm{~J}$ after five days of storage (Fig. 5).

The energy absorbed by the sample during impact is the energy converted into heat, oscillation energy and that of local internal damage. The average values of the adsorbed energy decreased with time from values that reached from $23.610^{-3} \mathrm{~J}$ for the fresh root samples to $11.810^{-3} \mathrm{~J}$ after the five-day storage period (Fig. 6). In this case a statistically significant linear drop was also observed.

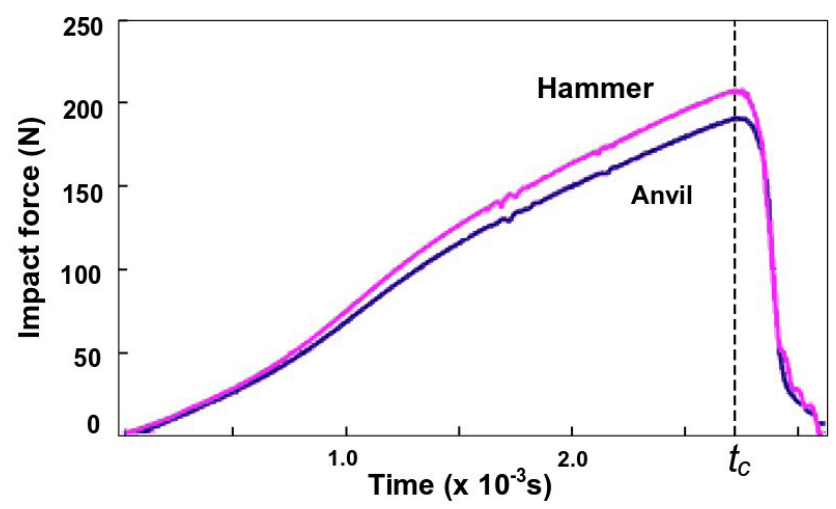

Fig. 3. Typical course of the sample response recorded by the sensors installed in the hammer and anvil during impact.

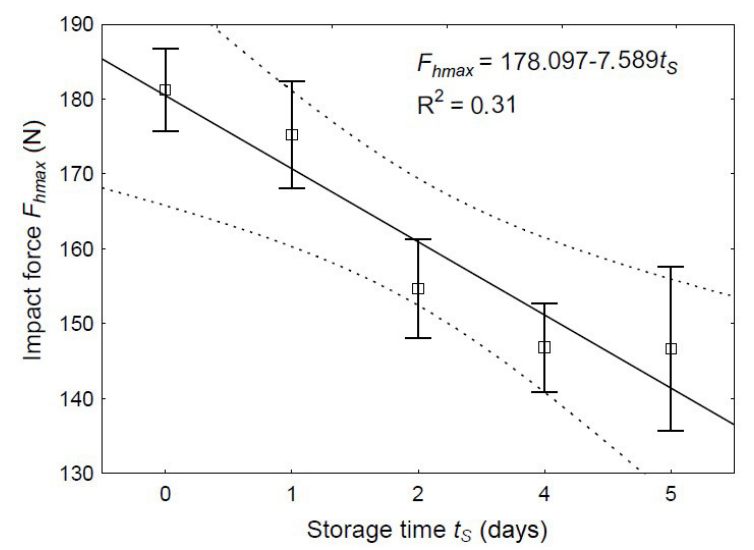

Fig. 4. Effect of storage time on the value of maximum force response on the hammer $F_{h \text { max. }}$

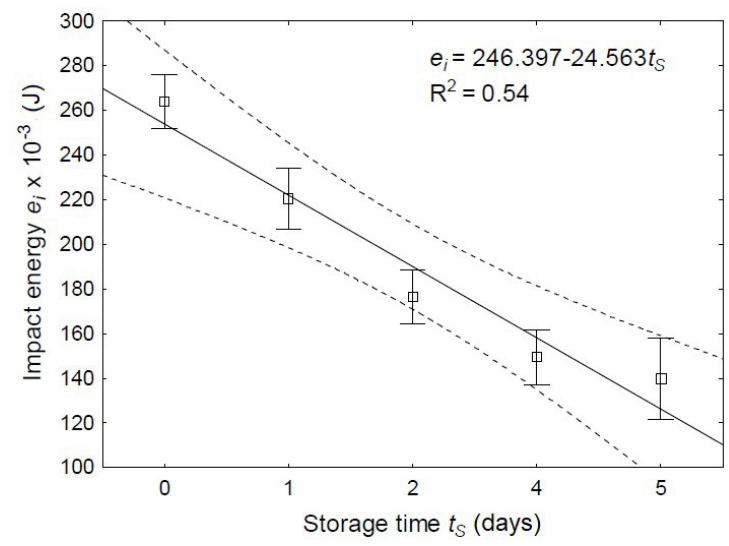

Fig. 5. Effect of storage time on the value of impact energy $e_{i}$ recorded by the sensor installed in the hammer.

The average values of the damaging stresses were in the range from 2.84 to $2.30 \mathrm{MPa}$ (Fig. 7). The average values of strains $\varepsilon_{d}$, at which the sample damage took place were in the range from 0.133 for the fresh roots to 0.105 for those that had exceeded five days of storage (Fig. 8). Both critical stress and strain showed a slight tendency to decrease as a function of storage time. 


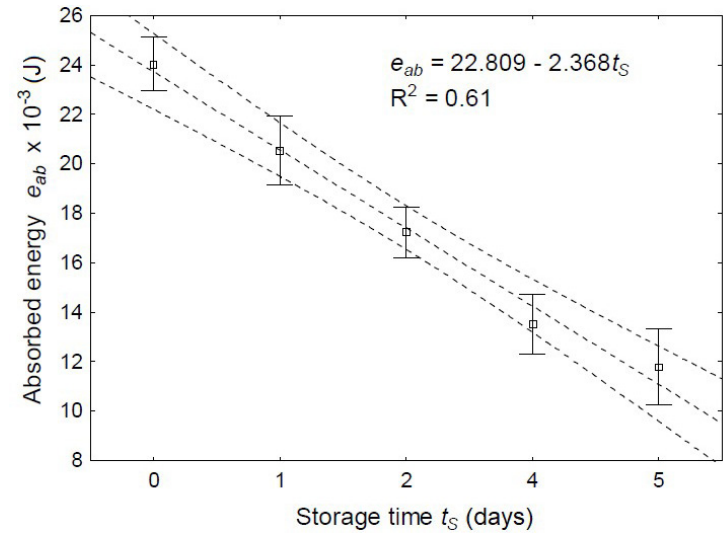

Fig. 6. Effect of storage time on the value of the energy absorbed by the sample during impact $-e_{a b}$.

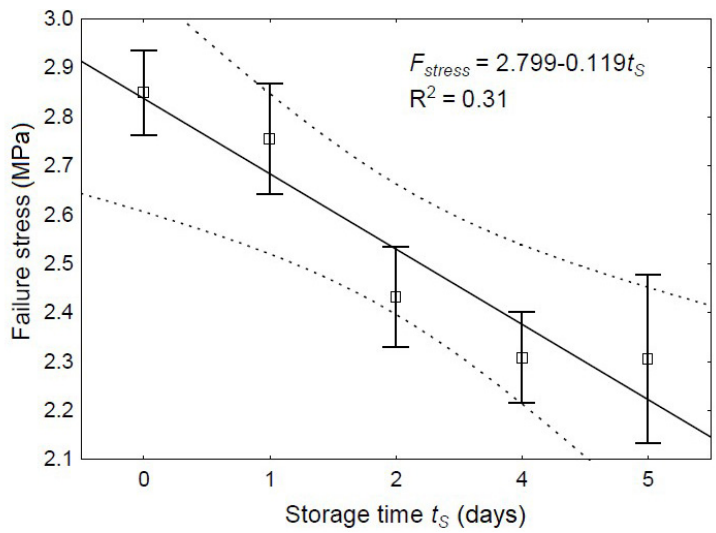

Fig. 7. Effect of storage time on the sample failure stress during impact.

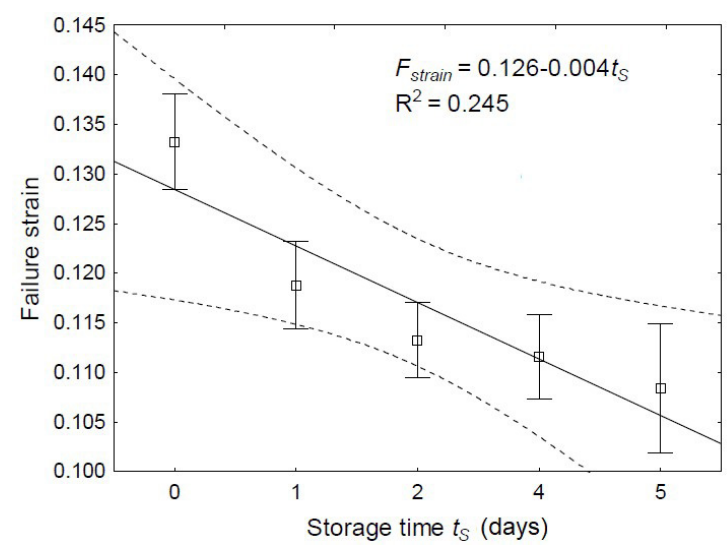

Fig. 8. Effect of storage time on the sample failure strain during impact.

No correlation between the elasticity modulus and the storage time was found. Its average values ranged from 20.73 to $23.28 \mathrm{MPa}$ (Fig. 9).

Figure 10 shows the evaluation methods of time of stress wave transition through the sample. The section $\Delta t$ indicates the time interval between the beginning of the increase in sample response force curves measured by sensors placed in the hammer and anvil. The courses of the

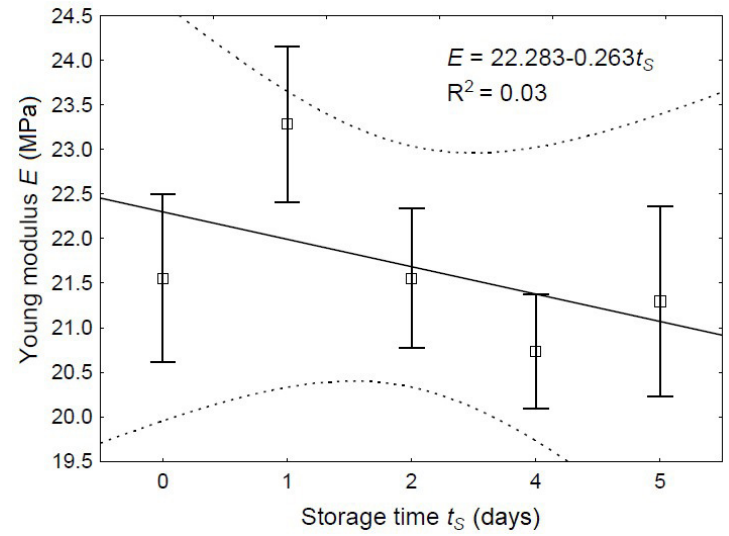

Fig. 9. Effect of storage time on the Young's modulus of the samples during impact.

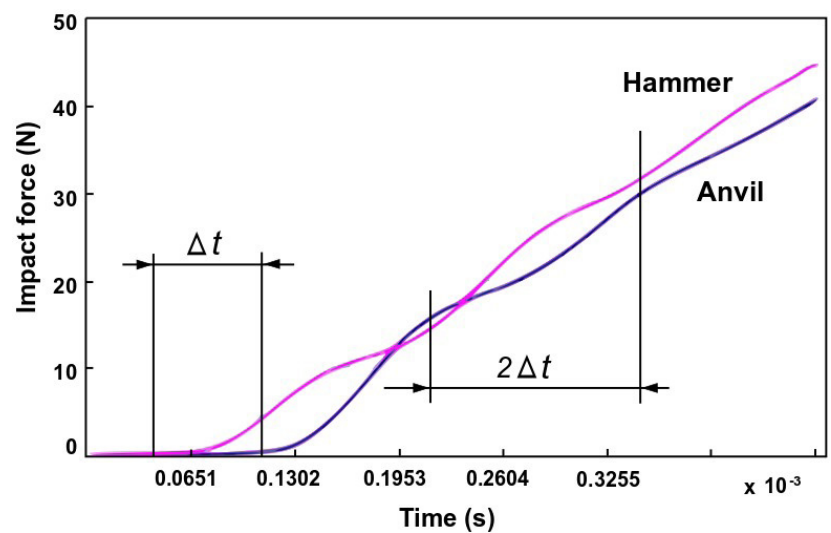

Fig. 10. Evaluation methods of the time of stress wave propagation through the sample as a result of impact.

response forces measured at both ends of sample showed fluctuations in the values of the sinusoid shape which demonstrated a reflection of the stress wave from the sample end and a return to its origin. The time interval $2 \Delta t$ determined on the base of sinusoid was consistent with the time interval $\Delta t$ determined on the base of the starting points of both response force-time curves.

The values of force and stress recorded during the experiment which were necessary for sample damage were characterized by remarkable scatter and their values demonstrate a weakly decreasing correlation with storage time. A very high degree of correlation was found in the case of the impact energy whose average values decreased with the storage time. Damage to the samples stored for four days required about a $40 \%$ lower impact energy compared to those obtained from roots directly after harvesting. The results obtained indicate a rapid loss of turgor pressure by the roots after harvest which, with their large mass results in a greater susceptibility to damage. A similar relationship was found for the energy absorbed by the sample during impact. The value of the energy dispersed in the sample before damage decreased with storage time which proves a greater susceptibility of stored roots to impact load. As previously mentioned the tendency for a small drop in 
the critical stress values was observed during the experiment. These values were similar to those obtained by the other authors under quasi-static load conditions (Gorzelany and Sosnowski, 2003; Nedomova et al., 2017). Whereas the values of critical strains were over three times greater than those obtained by other researchers under the quasistatic load conditions (Nedomova et al., 2017). The time required to damage a sample at an impact velocity of $1 \mathrm{~m}$ $\mathrm{s}^{-1}$ is about $2.510^{-3} \mathrm{~s}$. In the case of a typical compression test of a $20 \mathrm{~mm}$ high sample at $20 \mathrm{~mm} \mathrm{~min}^{-1}$ it may take as long as $10 \mathrm{~s}$. Besides tissue structures, the plant materials, which contain a large quantity of water, also contain some amounts of gases in the intercellular spaces. Under a load they translocate in the material which shows creep and stress relaxation phenomena typical of viscoelastic bodies. During the impact whose duration time is about 4000 times shorter compared with typical compression, the flow of fluids and gases in the intercellular spaces is not possible. Elastic deformations and local fractures or the stratification of single cells and tissues that occured before sample damage are observed as a rapid increase and drop of response force. These observations confirm the elasticity modulus determined during the experiment whose values were three times higher compared with those obtained by other researchers using compression tests (Alizadeh and Segerlind, 1997; Gorzelany and Sosnowski, 2003; Bentini et al., 2005). A significant increase in the stresses inside the sample as a function of strain confirms the different character of the response of the studied material which may be treated as elastic. The experimental results provoke the question: What are the actual causes of sugar beet tissue damage? Do the causes go beyond the boundary stress or strain values? Furthermore, the experimentally obtained values of damaging stresses under impact conditions did not differ significantly from those obtained by the other authors during the compression tests. However, the values of critical strains were more than three times lower. This confirms the veracity of critical stress criterion for sugar beet roots. The velocities of stress wave propagation in the samples during impact were in the range from 220 to $384 \mathrm{~m} \mathrm{~s}^{-1}$ and were not correlated with the experimental parameters.

\section{CONCLUSIONS}

1. The energy values of required for sample damage as well as those absorbed by the sample during impact decreased with storage time which proves higher root susceptibility to damage over the course of storage time.

2. The values of the critical stresses obtained under the impact conditions were comparable and those of critical strains were three times smaller than those reported in the literature but obtained under quasi-static load conditions. The experiment confirmed the veracity of critical stress criterion for sugar beet roots.
3. Under impact loading conditions no significant differences between all of the obtained parameters were observed for samples cut crosswise and lengthwise relative to the root axis.

Conflict of interest: The Authors do not declare conflict of interest.

\section{REFERENCES}

Abedi G. and Ahmadi E., 2014. Bruise susceptibilities of Golden Delicious apples as affected by mechanical impact and fruit properties. J. Agr. Sci-Cambridge, 152(3), 439-447. https:// doi.org/10.1017/s0021859613000038

Alizadeh H. and Segerlind L.J., 1997. Some material properties of sugar beet roots. Appl. Eng. Agric., 13(4), 507-510. https://doi.org/10.13031/2013.21619

Bajema R.W., Hyde G.M., and Peterson K., 1998. Instrumentation design for dynamic axial compression of cylindrical tissue samples. Trans. ASAE, 41(3), 747-754. https://doi.org/10.13031/2013.17203

Bartlett D.I., 1998. Development of an electronic damage analogue for sugar beet. Asp. Appl. Biol., 52. Protection and Production of Sugar Beet and Potatoes, 185-190

Bentini M., Caprara C., Rondelli V., and Calieti M., 2002. The use of an electronic beet to evaluate sugar beet damage at various forward speeds of a mechanical harvester. Trans. ASAE, 45(3), 547-552. https://doi.org/10.13031/2013.8848

Bentini M., Caprara C., and Rondelli V., 2005. Mechanical properties of sugar beet roots. Trans. ASAE, 48(4), 14291439. https://doi.org/10.13031/2013.19168

Celik H.K., Rennie A.E.W., and Akinci I., 2011. Deformation behaviour simulation of an apple under drop case by finite element method. J Food Eng., 104(2), 293-298. https://doi. org/10.1016/j.jfoodeng.2010.12.020

Gancarz M., 2016. Correlation between cell size and blackspot of potato tuber parenchyma tissue after storage. Postharvest Biol. Technol., 117, 161-167. https://doi.org/10.1016/j. postharvbio.2016.03.004

Gancarz M., Konstankiewicz K., and Zagórska K., 2014. Cell orientation in potato tuber parenchyma tissue. Int. Agrophys., 28, 15-22. https://doi.org/10.2478/ intag-2013-0023

Golacki K., Stropek Z., Kołodziej P., Gladyszewska B., Zaremba M., and Rejak A., 2014. Effect of additives on strength characteristics of a biodegradable starch film (in Polish). Przem. Chem., 93(5), 728-731. https://doi. org/10.1016/j.aaspro.2015.12.038

Gorzelany J. and Matlok N., 2014. The study of selected mechanical and chemical properties of sugar beet roots. Food Ind. Eng., 3-4(11), 11-14.

Gorzelany J. and Sosnowski S., 2003. Effect of some factors on mechanical properties of tissue of sugar beet roots. Acta Agroph., 2(1), 73-82.

Hopkinson I.P. and Houghton B.J., 1998. Electronic sugar beet measurements: Assessments of beet handling and harvesting sugar losses. Asp. Appl. Biol., 52. Protection and Production of Sugar Beet and Potatoes, 169-172. https:// doi.org/10.3403/02148687

Karim A., Rahman M.M., Pham N.D., and Fawzia S., 2018. Food microstructure as affected by processing and its effect 
on quality and stability. In: Food Microstructure and Its Relationship with Quality and Stability. Elsevier (Ed. Devahastin Sakamon), United Kingdom, 43-57. https://doi. org/10.1016/b978-0-08-100764-8.00003-4

Kołodziej P., Golacki K., Stropek Z., Boryga M., and Gladyszewska B., 2014. Studies on thermoplastic starch film properties under impact load conditions. Przem. Chem., 93(8), 1375-1378. https://doi.org/10.1016/j. aaspro.2015.12.038

Lewis R., Yoxall A., Canty L. A., and Reina Romo E., 2007. Development of engineering design tools to help reduce apple bruising. J. Food Eng., 83(3), 356-365. https://doi. org/10.1016/j.jfoodeng.2007.03.005

Nedomova Š., Kumbar V., Pytel R., and Buchar J., 2017. Mechanical properties of sugar beet root during storage. Int. Agrophys., 31, 507-513. https://doi.org/10.1515/ intag-2016-0081

Opara L.U., 2007. Bruise susceptibilities of "Gala" apples as affected by orchard management practices and harvest date. Postharvest Biol. Technol., 43, 47-54. https://doi. org/10.1016/j.postharvbio.2006.08.012

Ozbek I.Y., Boydas M.G., Kara M., and Demir B., 2014. Low cost measurement setup based on a piezoelectric microphone for estimating apple bruising using Shannon entropy. Postharvest Biol. Technol., 98, 23-29. https://doi. org/10.1016/j.postharvbio.2014.06.014

Pan L., Lu R., Zhu Q., McGarth J.M., and Tu K., 2015. Measurement of moisture, soluble solids, sucrose content and mechanical properties in sugar beet using portable visible and near-infrared spectroscopy. Postharvest Biol. Technol., 102, 42-50. https://doi.org/10.1016/j. postharvbio.2015.02.005

Pilbrow J., 1997. Harvester evaluation using the electronic beet. British Sugar, 65(3), 14-15.

Polat R., Aktas T., and Ikinci A., 2012. Selected Mechanical Properties and Bruise Susceptibility of Nectarine Fruit. Int. J. Food Prop., 15, 1369-1380. https://doi.org/10.1080/1094 2912.2010.498546

Ragni L. and Berardinelli A., 2001. PH - Postharvest Technology: Mechanical behavior of apples and damage during sorting and packaging. J. Agric. Eng. Res., 78(3), 273-279.

Schuh J.P., Fechner W., and Uebe N., 1997. Untersuchungen zur Anwendung elektronischer Ruben in der Zuckerrubenernte. Agrartechnische Forschung, 3(1), 59-65.
Shafie M.M., Rajabipour A., Castro-Garcia S., JimenezJimenez F., and Mobli H., 2015. Effect of Fruit Properties on Pomegranate Bruising. Int. J. Food Prop., 18, 18371846. https://doi.org/10.1080/10942912.2014.948188

Skalicky J., 2003. Research of sugar-beet tubers mechanical properties. Res. Agr. Eng., 49(3), 80-84. https://doi. org/10.17221/4956-rae

Stropek Z. and Golacki K., 2016a. Methodological aspects of determining apple mechanical properties during impact. Int. J. Food Prop., 19, 1325-1334. https://doi.org/10.1080/1 0942912.2015.1063069

Stropek Z. and Golacki K., 2016b. Quantity assessment of plastic deformation energy under impact loading conditions of selected apple cultivars. Postharvest Biol. Technol., 115, 9-17. https://doi.org/10.1016/j.postharvbio.2015.12.011

Stropek Z. and Golacki K., 2018. Viscoelastic response of apple flesh in wide range of mechanical loading rates. Int. Agrophys., 32, 335-340. https://doi.org/10.1515/ intag-2017-0023

Stropek Z. and Golacki K., 2019a. Impact characteristics of pears. Postharvest Biol. Technol., 147, 100-106. https://doi. org/10.1016/j.postharvbio.2018.09.015

Stropek Z. and Gołacki K., 2019b. Stress relaxation of apples at different velocities and temperatures. Trans. ASABE, 62(1), 115-121. https://doi.org/10.13031/trans.12993

Stropek Z., Gołacki K., Kołodziej P., Gladyszewska B., Samociuk W., and Rejak A., 2014. Effect of polyvinyl alcohol and keratin on stress relaxation course in thermoplastic starch. Przem. Chem., 93, 364-367. https://doi. org/10.1016/j.aaspro.2015.12.038

Trnka J., Kumbar V., Nedomova S., Pytel R., and Buchar J., 2018. Influence of sugar beet storage duration on root response to non-destructive impacts. Int. Agrophys., 32, 421-428. https://doi.org/10.1515/intag-2017-0032

Wiltshire J.J.J. and Cobb A.H., 2000. Bruising of beet roots and consequential sugar loss: current understanding and research needs. Ann. Appl. Biol., 136, 159-166. https://doi. org/10.1111/j.1744-7348.2000.tb00021.x

Yen M. and Wan Y., 2003. Determination of textural indices of guava fruit using discriminate analysis by impact force. Trans. ASAE, 46(4), 1161-1166. https://doi. org/10.13031/2013.13939

Zdunek A., Gancarz M., Cybulska J., Ranachowski Z., and Zgórska K., 2008. Turgor and temperature effect on fracture properties of potato tuber (Solanum tuberosum $\mathrm{cv}$. Irga). Int. Agrophys., 22, 80-97. 